in the legs and elsewhere, as will be described in a separate paper.

I gratefully acknowledge the help which I have received from Dr. Eleanor Mears and the Council for the Investigation of Fertility Control, also the financial assistance from the Lalor Foundation. I also thank Dr. Hilary Hill, Dr. J. Pryse-Davies, Dr. F. J. Morley, Dr. B. Schooling, Dr. R. Tozer, Dr. T. King, Dr. J. Scott-Wilson, and Mrs. B. Lamb for contributing to this study. I am indebted to Mr. B. Mathalone and Dr. A. Bron, who carried out ophthalmological examinations and photography at Moorfields Eye Hospital, and to Mrs. Ann Davis for statistical analysis.
REFERENCES

Bickerstaff, E. R., and Holmes, J. MacD. (1967). Brit. med. 7., 1, 726. Grant, E. C. G. (1964). 7. Reprod. Fertil., 8, 275.

Grant, E. C. G. (1965). Lancet, 1, 1143.

Grant E C. G (1967) of Obstet. Gynaec. Brit. Cwlth, 74, 908.

Illis, L., Kocen, R S., McDonald, W. I., and Mondkar, V. P. (1965). Brit. med. Y., 2, 1164 .

Mazhar K. Hefnawi, F., Kadri, Sh., El-Ganzoury, B. A., Askalani, A. H., and Eil-Tagi, A. H." (1965), Paper presented at symposium on Family Planning, Cairo.

Mears, E. (1961). Brit. med. 9., 2, 1179

Mears, E. (1967). In Excerpta Medica International Congress Series No. 133, p. 1005 . Amsterdam.

Mears, E., and Grant, E. C. G. (1962). Brit. med. 3., 2, 75.

Noyes, R. W. Hertig, A. T., and Rock, J. (1950). Ferril. Steril., 1, 3.

Walsh F B. Clark D. Thompson, R. S., and Nicholson, D. H. (1965). Arch. Ophthal., 74, 628.

\title{
Circadian Rhythm of Plasma 11-Hydroxycorticosteroids in Psychiatric Disorders
}

\author{
R. T. W. L. CONROY,* M.SC., PH.D., L.R.C.P.\&S.I. ; B. D. HUGHES, † M.B., D.P.M. \\ J. N. MILLS, $\ddagger$ M.A., D.M., M.D., B.SC.
}

Brit. med. F., 1968, 3, 405-407

\begin{abstract}
Cummary : Studies of the circadian rhythm in plasma 11-O.H.C.S. levels showed that a subgroup of affective psychotics had higher plasma 11-OHCS values as compared with schizophrenic and other psychotic subgroups, and a somewhat less regular rhythm. One patient with depression who was studied over 48-hour periods showed a reduction in plasma 11-OHCS levels with clinical recovery. An accentuated fall and rise in plasma 11-OHCS values in the night and early morning samples, respectively, was observed in the schizophrenic subgroup.
\end{abstract}

\section{Introduction}

Psychiatric disorders are sometimes associated with changes in physiological rhythms. Manic-depressive illness is an outstanding example, with daily variations in mood and symptoms and disruption of the normal pattern of sleep and wakefulness. Changes in the amplitude of water, potassium, sodium, and chloride excretory rhythms have recently been noted in this condition (Lobban et al., 1963 ; Elithorn et al., 1966). Abnormalities of urine volume and diurnal rhythm have been reported in schizophrenia (Gjessing, 1936; Hoskins, 1946 ; Randrup and Munkvad, 1966), and the onset of this disease is sometimes marked by a prolonged period of wakefulness (Bliss et al., 1959).

Adrenocortical secretion in healthy subjects is known (Pincus, 1943 ; Bliss et al., 1953) to have a 24-hour, or circadian, rhythm and has been shown to be very closely associated with the sleep-wakefulness cycle, peak plasma corticosteroid levels occurring shortly before awakening, and minimum values about midnight (Perkoff et al., 1959). Disturbances of adrenocortical secretion in psychiatric illness have been suspected for some time, particularly in depressive illness (Reiss, 1953) and to a lesser extent in schizophrenia (Hoagland et al., 1953).

We describe here observations on the circadian rhythm of plasma 11-OHCS in manic-depressive and schizophrenic patients and in patients suffering from psychiatric disorders not

- Lecturer, Department of Physiology, University of Manchester.

t Consultant Psychiatrist, Parkside Hospital, Macclesfield.

F Brackenbury Professor of Physiology, University of Manchester. considered to be associated with disturbances of the sleepwakefulness cycle. A pilot survey has already been reported (Conroy et al., 1968).

\section{Patients and Methods}

In one investigation 16 patients, all men, were divided into three subgroups, A, B, and C, consisting respectively of five schizophrenics, six affective psychotics, and five patients with psychotic illnesses not marked by disturbances of sleep. All the schizophrenics displayed first-rank Schneiderian symptoms. The six affective psychotics had a characteristic history of phasic alternation of mood together with early morning waking, significant self-reproach, constipation, bowel preoccupation, and anorexia in the depressive phases. Four of the six had a previous history of episodes of hypomania.

None of the schizophrenics complained of regular disturbance of sleep, while the depressed patients all complained of insomnia-in particular early morning wakefulness, which was present at the time of investigation.

All the schizophrenics were being treated with phenothiazines -mainly chlorpromazine and trifluoperazine-and the affective psychotics, who were all in the depressive phase, were receiving imipramine or amitriptyline.

The other psychotics comprised two patients with presenile dementia, two cerebral arteriosclerotics, and one patient with Korsakoff's syndrome.

The subjects were living under a similar regimen in a psychiatric hospital. With the exception of one schizophrenic all had been admitted at least three months before the investigation. Drug therapy was discontinued for the 24 hours preceding the first blood sample. The samples were obtained at $10.00,14.00,18.00,22.00,02.00,06.00$ hours, and again at 10.00 hours ( $\pm 1 / 4$ hour in each instance).

Four patients, all female, two of them affective psychotics and two suffering from schizophrenia, were observed in a second investigation extending over a period of up to 12 months. The two affective psychotics had a long history extending over 10 years of periods of depression alternating with hypomania with normality in between. Both schizo- 
phrenics had a long history (20 years + ) of characteristic symptomatology, including typical auditory hallucinosis, incongruity of affect, and somatic passivity feelings. In these subjects morning (09.00-10.00 hours) and evening (18.00-20.00 hours) samples were taken at intervals of one to six weeks. One of these patients, an affective psychotic, died during the course of the year.

A female patient who was admitted during an acute depressive phase of affective psychosis was also studied in the acute post-admission phase, after seven days' therapy with imipramine, and a year later. In each instance six-hourly blood samples were taken over 48 hours. On admission she was in stupor, immobile, and almost mute ; after seven days' therapy there was little apparent change clinically. Twelve months later she appeared to be clinically normal.

Blood samples were taken by venepuncture with disposable plastic syringes, transferred immediately to glass heparinized tubes, centrifuged as soon as possible to obviate any loss of steroids into the erythrocytes (Eik-Nes et al., 1953; Bush, 1954), refrigerated $\left( \pm 4^{\circ}\right.$ C.), and analysed within 72 hours for 11-OHCS (hydrocortisone and corticosterone). The fluorimetric method of Mattingly (1962), as modified by SpencerPeet et al. (1965), was employed, using a Locarte fluorimeter with a zinc arc lamp (peak transmission 468-72-81 $\mathrm{m} \mu$ : Sweat, 1954) and reading fluorescence at $530 \mathrm{~m} \mu$.

\section{Results}

Mean plasma corticosteroid values for the three subgroups at each time of sampling during the 24-hour, or transverse, survey are shown in Fig. 1. Peak values occurred in the 06.00-hour samples-that is, those taken on waking-in all three subgroups (Fig. 1). Minimal values for the schizophrenic and non-sleep disturbance psychotic subgroups were in the 02.00-hour samples, but in the affective psychotic subgroup, however, at 14.00 and 18.00 hours. Values in this subgroup were higher than in either of the other subgroups at all sampling times except at 06.00 hours and at the second 10.00 hours.

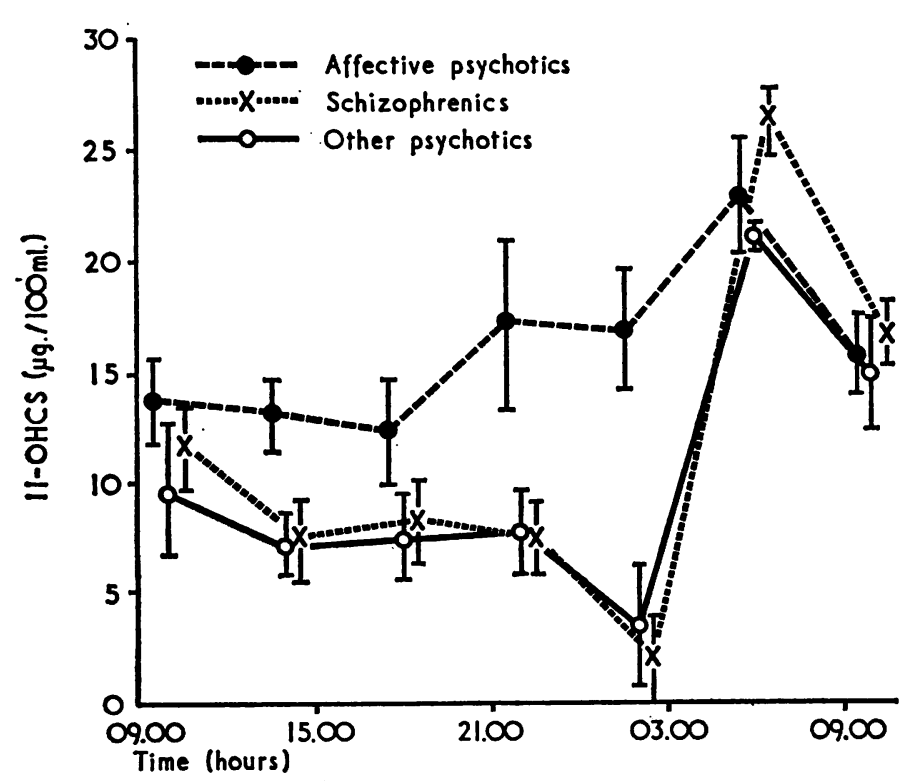

FIG. 1.-Transverse survey-mean plasma 11-OHCS levels in three subgroups of psychotic patients.

The pattern in individual affective psychotics was markedly irregular, whereas in the other subgroups individual patterns were much the same as the mean of the subgroups. In particular, all five schizophrenics and four of the five patients in subgroup $C$ showed a steep rise in 11-OHCS levels to a marked peak at 06.00 hours, but only two of the six affective psychotics showed a sharp rise at this time. It will be seen in Fig. 1 that mean concentration over the 24 hours for the affective psychotic subgroup was higher than in either of the other subgroups. 11 -OHCS values below $7 \mu \mathrm{g} . / 100 \mathrm{ml}$. were not seen in any affective psychotic at any sampling time, whereas in the other subgroups every subject showed values below this level on one or more occasions.

Mean a.m. and p.m. values for the 12 -month, or longitudinal, study are shown in the Table. The mean values in all four patients were higher in the morning, though on some individual days the evening values were higher. Both pairs of patients behaved similarly, which is perhaps not surprising, since, as Fig. 1 indicates, the times were not well chosen to demonstrate the existence of a rhythm in either group of patients.

Longitudinal Survey: Mean Morning and Afternoon Plasma 11-OHCS

\begin{tabular}{c|c|c|c}
\hline \multirow{2}{*}{ Patient } & \multirow{2}{*}{ Diagnosis } & \multicolumn{2}{|c}{ Mean 11-OHCS ( $\mu \mathrm{g} . / 100 \mathrm{ml}$. ) } \\
\cline { 3 - 4 } & & $0900-10.00 \mathrm{hrs}$ & $18.00-20.00 \mathrm{hrs}$. \\
\hline A & Schizophrenia & $9 \cdot 0$ & 7.3 \\
B & Schizophrenia & $11 \cdot 0$ & $8 \cdot 9$ \\
C & Affective psychosis & $14 \cdot 0$ & $11 \cdot 8$ \\
\hline & Affective psychosis & $10 \cdot 8$ & 6.9 \\
\hline
\end{tabular}

The plasma 11-OHCS values for the individual case of affective psychosis admitted while in the acute depressive stage are shown in Fig. 2. A clearly marked circadian rhythm was seen in the series of observations taken immediately after admission and a week later. Very similar values were seen in both series, with large amplitudes and high peak levels of 35.6 to $42.7 \mu \mathrm{g} . / 100 \mathrm{ml}$. in the 06.00 -hour samples. Twelve months later the circadian pattern continued to be prominent with 11-OHCS values which were still rather high but noticeably lower than in the acute stage of her illness.

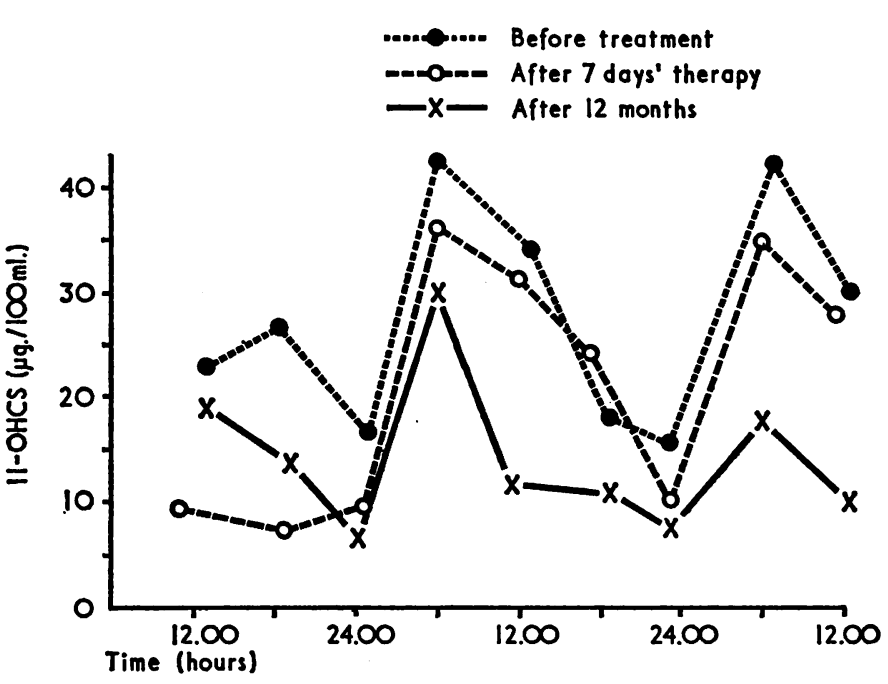

FIG. 2.-Plasma 11-OHCS levels in an affective psychotic before and after clinical recovery.

\section{Discussion}

Board et al. (1956, 1957) reported raised plasma hydrocortisone levels in depressed patients in morning blood samples, as did Gibbons and McHugh (1962), Gibbons (1964), and Hullin et al. (1967). Brooksbank and Coppen (1967), comparing morning (08.00-08.15 hours) and evening (21.00-21.15 hours) samples, considered that morning plasma 11-OHCS values were little above normal but that evening plasma concentrations were more closely related to the patients' clinical state. McClure (1966) observed the pattern over 24 hours by taking samples at $06.45,11.45$, and 22.00 hours, and, thus making a serious effort to allow for circadian variations, he 
found elevated plasma 11-OHCS in depressed subjects as compared with controls at all three sampling times. Bridges and Jones (1966), who also observed plasma 11-OHCS levels over 24 hours, reported lower values in the depressed patients as compared with controls at two out of their three sampling times. Knapp et al. (1967) took a series of seven samples from a group of depressed patients at four-hourly intervals beginning at $\mathbf{0 8 . 0 0}$ hours, and found significantly elevated 11-OHCS levels at 04.00 hours. Conroy et al. (1968) reported higher mean values in a group of five affective psychotics as compared with two other groups of psychotic patients in samples taken at approximately $15.00,22.00$. 07.00, 10.00, and 15.00 hours.

The present results provide further evidence that plasma corticosteroid values tend to be raised in depressive illness and, because serial samples were taken, it may be seen that this rise may be present throughout the 24 hours, but is perhaps (see Fig. 1) more readily observed in late evening or night samples and may even be obscured in morning blood samples. It also appears that the phase or timing of the circadian rhythm of the plasma corticosteroids may be upset in some depressed patients. In this respect it is interesting to note that Doig et al. (1966), who measured plasma 11-OHCS values at $24.00,03.00$, and 06.00 hours, recorded peak levels at 03.00 hours in 7 out of 10 depressed patients studied, and that on recovery five out of the six cases they were able to re-examine showed a shift in peak values to 06.00 hours. None the less, a circadian rhythm of corticosteroid secretion persists even in the acutely depressed state, as is well shown in the case depicted in Fig. 2 ; and in another study we did not note any evidence of phase-shifting in samples taken at about 22.00 and 07.00 hours (Conroy et al., 1968). The tendency for plasma 11-OHCS levels to fall on clinical recovery (Gibbons and McHugh, 1962 ; Bridges and Jones, 1966; Hullin et al., 1967) is also illustrated in this patient. Here again this might not have been so clearly evident had serial samples not been taken.

Little work seems to have been done on plasma 11-OHCS levels in schizophrenia. Sachar et al. (1963) have, however, reported marked rises in urinary 17-hydroxycorticosteroids during acute schizophrenic reactions. The night and early morning pattern of plasma 11-OHCS in our schizophrenic sub- group may almost be described as supernormal, with a fall to zero levels in four out of five patients at $\mathbf{0 2 . 0 0}$ hours followed by a very sharp rise to high values at 06.00 hours.

The most remarkable finding is the close similarity of the plasma corticosteroid rhythm to that observed in healthy subjects, even in patients with gross psychiatric abnormality, and, most notably, in one who was continuously stuporous.

\section{REFERENCES}

Bliss, E. L., Clark, L. D., and West, C. D. (1959). Arch. Neurol. Psychiat. (Chic.), 81, 348

Bliss, E. L., Sandberg, A. A., Nelson, D. H., and Eik-Ness, K. (1953). 7. clin. Invest., 32, 818.

Board, F., Persky, H., and Hamburg, D. A. (1956). Psychosom. Med., 18,324

Board, F., Wadeson, R.. and Persky, H. (1957). Arch. Neurol. Psychiat. (Chic.), 78, 612.

Bridges, P. K., and Jones, M. T. (1966). Brit. F. Psychiat., 112, 1257

Brooksbank, B. .W. L., and Coppen, A. (1967). Brit. F. Psychiat., 113,

Bush, I. (1954). Kecent Progr. Hormone Res., 9, 449.

Conroy, R. T. W. L., Elliot, A. L., Hughes, B. D., and Mills, J. N. (1968). F. Physiol. (Lond.), 196, 129P.

Doig, R. J., Mummery, R. V., Wills, M. R., and Elkes, A. (1966). Brit. 7. Psychiat., 112, 1263

Eik-Ness, K., Nelson, D. H., and Samuels, L. T. (1953). Y. clin. Endocr., 13,1280 .

Elithorn, A., Bridges, P. K., Lobban, M. C., and Tredre, B. E. (1966). Brit. med. F., 2, 1620 .

Gibbons, J. L. (1964). Arch. gen. Psychiat., 10, 572

Gibbons, J. L. (1964). Arch. gen. Psychiat., 10, 572.

Gibbons, J. L., and McHugh, P. R. (1962). 7. psychiat. Res

Gjessing, R. (1936). Arch. Psychiat. Nervenkr., 104, 355.

Hoagland, H. et al. (1953). Arch. Neurol. Psychiat. (Chic.), 69, 470.

Hullin, R. P., Bailey, A. D., McDonald, R., Dransfield, G. A., and Milne, H. B. (1967). Brit. F. Psychiat., 113, 593.

Knapp, M. S., Keane, P. M., and Wright, J. G. (1967). Brit. med. J., $2,27$.

Lobban, M., Tredre, B., Elithorn, A., and Bridges, P. (1963). Nature (Lond.), 199, 667.

Mattingly, D. (1962). \%. clin. Path., 15, 374

McClure, D. J. (1966). \%. psychosom. Res., io, 189

Perkof, G. T., et al. (1959). Y. clin. Endocr., 19, 432

Perkof, G. T.̈ et al. (1959). F. clin. Endoc

Randrup, A., and Munkvad, I. (1966). Brit. F. Psychiat., 112, 173.

Reiss, M. (1953). Int. Rec. Med., 166, 196

Sachar, E. J., Mason, J. W., Kolmer, H. S., and Artiss, K. L. (1963). Psychosom. Med., 25, 510 .

Spencer-Peet, J., Daly, J. R., and Smith, V. (1965). J. Endocr., 31, 235. Sweat, M. L. (1954). Analyt. Chem., 26, 773.

\title{
Trial of Phenoxymethylpenicillin, Phenethicillin, and Lincomycin in Treatment of Staphylococcal Sepsis in a Casualty Department
}

\author{
D. J. E. PRICE,* M.B., B.S., F.R.C.S. ; F. W. O’GRADY, † M.D., M.SC., M.C.PATH. \\ R. A. SHOOTER, $\ddagger$ M.D., M.R.C.P., F.C.PATH. ; P. C. WEAVER,§ M.B., B.S., F.R.C.S.ED.
}

Brit. med. F., 1968, 3, 407-409

\begin{abstract}
Summary: A comparative trial of phenoxymethylpenicillin (penicillin V), phenethicillin (Broxil), and lincomycin (Lincocin) against superficial staphylococcal infections seen in a casualty department showed no difference in the efficacy of the three agents, though half the staphylococci isolated were resistant to penicillin. Possible reasons include the fact that antibiotic treatment may not affect superficial staphylococcal infections, or that the organisms concerned may have been weak formers of penicillinase.
\end{abstract}

Falf the patients treated with lincomycin complained of diarrboea and $5 \%$ of those treated with phenethicillin suffered from nausea.

\begin{abstract}
Introduction
In this hospital it is usual to prescribe penicillin for the antibiotic treatment of patients seen in the casualty department with staphylococcal sepsis. If the lesion is open the organism is cultured and, if necessary, the antibiotic is changed to one appropriate to the bacteriological sensitivities. Phenoxymethylpenicillin (penicillin V) by mouth has been found to be almost as satisfactory as penicillin by injection (Burn et al.,

\footnotetext{
- Institute of Neurological Science, Rillearn Hospital, near Glasgow. Formerly Sorting Officer, St. Bartholomew's Hospital, London E.C.1. 5 St. Albans City Hospital, 10 Gombards, St. Albans, Herts. Formerly Sorting Officer, St. Bartholomew's Hospital, London E.C.1.
} † Professor of Bacteriology, St. Bartholomew's Hospital, London E.C.1. ₹ Professor of Bacteriology, St. Bartholomew's Hospital, London E.C.1.
\end{abstract}

